\section{Numerical Study of Impeller Trimming on a Centrifugal Pump Test Unit}

\author{
R. Aurick Nugraha Prawito, Vivien S. Djanali Alif Arif Wicaksono \\ Department of Mechanical Engineering, Institut Teknologi Sepuluh Nopember, Surabaya 60111, Indonesia \\ Received: 11 January 2019, Revised: 8 March 2019, Accepted: 18 March 2019
}

\begin{abstract}
Centrifugal pumps have an essential role in various industries. Impeller trimming is often performed to optimize the pump performance at a particular operating point. Impeller trimming refers to a reduction in the impeller outer diameter and thus causes a change in the velocity triangle on the impeller of a centrifugal pump. Three-dimensional, unsteady simulations were conducted numerically using moving mesh. This centrifugal pump has a backward-curved impeller with six blades, with an outer diameter of $120 \mathrm{~mm}$ and an outlet angle of $10^{\circ}$, which will be trimmed to a diameter of $114 \mathrm{~mm}$. Trimming the impeller reduced the outer diameter so that the outlet angle of the relative velocity to the tangential direction, $\beta_{2}$, automatically changed according to the blade shape. The simulation was done by varying the pump discharge. The simulation results were compared with the experimental results. The results obtained in this study include quantitative data and qualitative data. Qualitative data was the appearance of velocity profiles, velocity vectors, and pressure contours. Meanwhile, the quantitative data were in the form of suction pressure, discharge pressure, head calculation, and hydraulic power. The comparison of the results of the numerical simulation with the experimental results have the same trend, although the simulation tended to underestimate the head and hydraulic power. A decrease in head and hydraulic power of the pump due to trimming the impeller from the lowest discharge to the highest discharge is as much as $13 \%$ to $24 \%$.
\end{abstract}

Keywords: Backward-curved impeller, centrifugal pump, CFD, impeller trimming

\section{Introduction}

Pumps have a vital role in the industrial world. A pump is a mechanical device that functions to move liquid from one place to another. There are many types of pumps used, one of which is the centrifugal pump. However, it is often found that a pump does not operate at its optimal point. Therefore, many kinds of research have been carried out on centrifugal pumps, both experimentally and numerically.

Because of the importance of a pump, it is desirable that the pump can operate at its optimal point. Many modifications are made to improve the performance of a pump. One of the modifications made in this research was trimming on the impeller, namely cutting the impeller outer diameter. Impeller trimming is performed to match operating points to specifications.

Previous studies on centrifugal pump impeller trimming have been performed. Energy savings from pump impeller trimming in heating and cooling system was estimated [1]. An analytical approach to calculate the head and flow capacity was studied [2]. Another prediction method was studied in [3]. Li [4] conducted experiments on trimming on the centrifugal viscous oil pump, in which the value of the trimming exponents related to the affinity law was obtained. Another experiment showed that the correlation of the head coefficient to the flow coeffi- cient of the trimmed impeller was similar to that obtained from the affinity law [5]. The shape of the cutting in impeller trimming and its effect on the performance was studied in [6]. Investigation on pump performance can be performed numerically such that conducted by [7, 8] Numerical simulations on impeller trimming have also been performed [9]. It was found out that trimming the impeller shifted the best efficiency point to the lower flow capacity. Zhou et al. [10] studied numerically the effect of trimming method on the performance of the pump. The current study is based on an experimental study conducted by Wicaksono [11]. Similar configuration for the standard impeller has been studied [7].

\section{Method}

This study used the configurations of the impeller of the Armfield FM50 centrifugal pump unit, as documented in [11]. Figure 1 below is the condition of the impeller and volute in the Armfield FM 50 centrifugal pump installation, while in Figure 2 is the backward form of the initial impeller $(D=120 \mathrm{~mm})$ and the impeller that has been trimmed $(D=114 \mathrm{~mm})$. The two impellers were simulated in this study.

By trimming, the outlet angle of the relative velocity to the tangential direction, $\beta_{2}$, will change as the outer diameter decreases. The ratio of the angle $\beta_{2}$ with the

*Corresponding author. Email: vivien_s@me.its.ac.id 
outer diameter is shown in Table 1 . The tests were performed at three different flow capacities of $0.1 \mathrm{~L} / \mathrm{s}\left(Q_{1}\right)$, $0.6 \mathrm{~L} / \mathrm{s}\left(Q_{2}\right)$, and $1 \mathrm{~L} / \mathrm{s}\left(Q_{3}\right)$, at a constant rotational speed of $1050 \mathrm{rpm}$. To get a varying discharge at a constant rotation of $1050 \mathrm{rpm}$, it was regulated by setting the valve or throttling on the inlet (suction) side.

The three-dimensional simulation domain is shown in Figure 3. Unstructured tetrahedral mesh was used with refinement on the impeller blade surface using a boundary layer mesh, as shown in Figure 4, with a total of around 1 million cells. Grid independency was performed, and this amount of cells was chosen, which has a relative error value of $0.09 \%$ to the higher number of cells.

Table 1. Comparison of the outer diameter with the angle $\beta_{2}$.

\begin{tabular}{|c|c|c|}
\hline Name & $\begin{array}{c}\text { Outer } \\
\text { Diameter }\end{array}$ & $\beta_{2}$ Angle \\
\hline Standard & $120 \mathrm{~mm}$ & $10^{\circ}$ \\
\hline Trimmed & $114 \mathrm{~mm}$ & $15^{\circ}$ \\
\hline
\end{tabular}
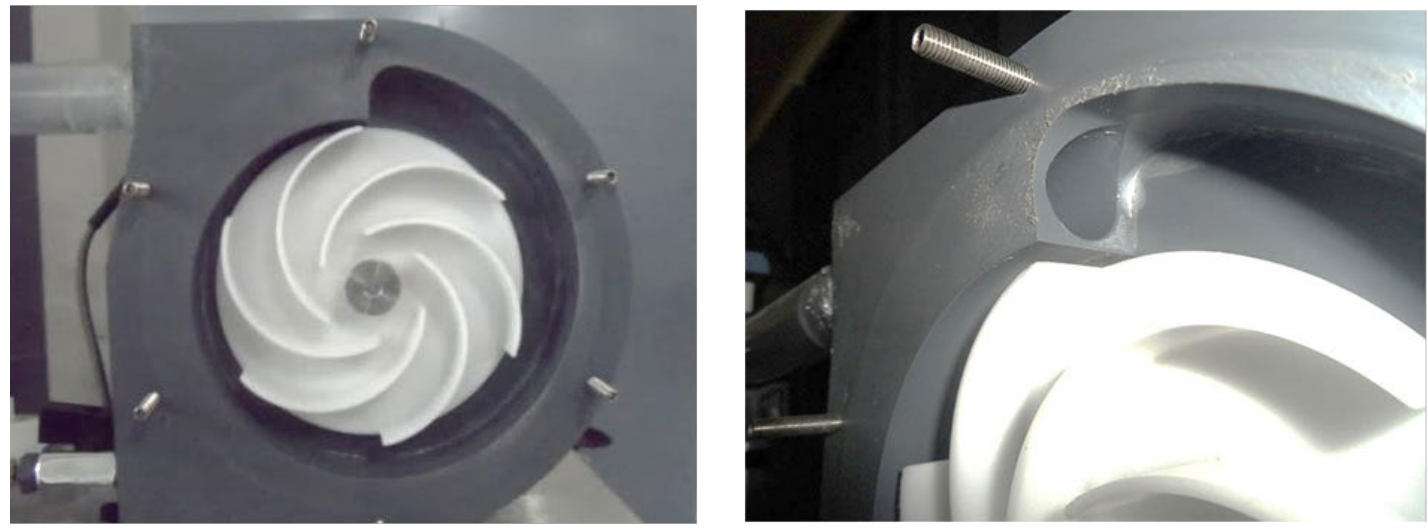

Figure 1. The impeller and volute chamber in the pump test installation.
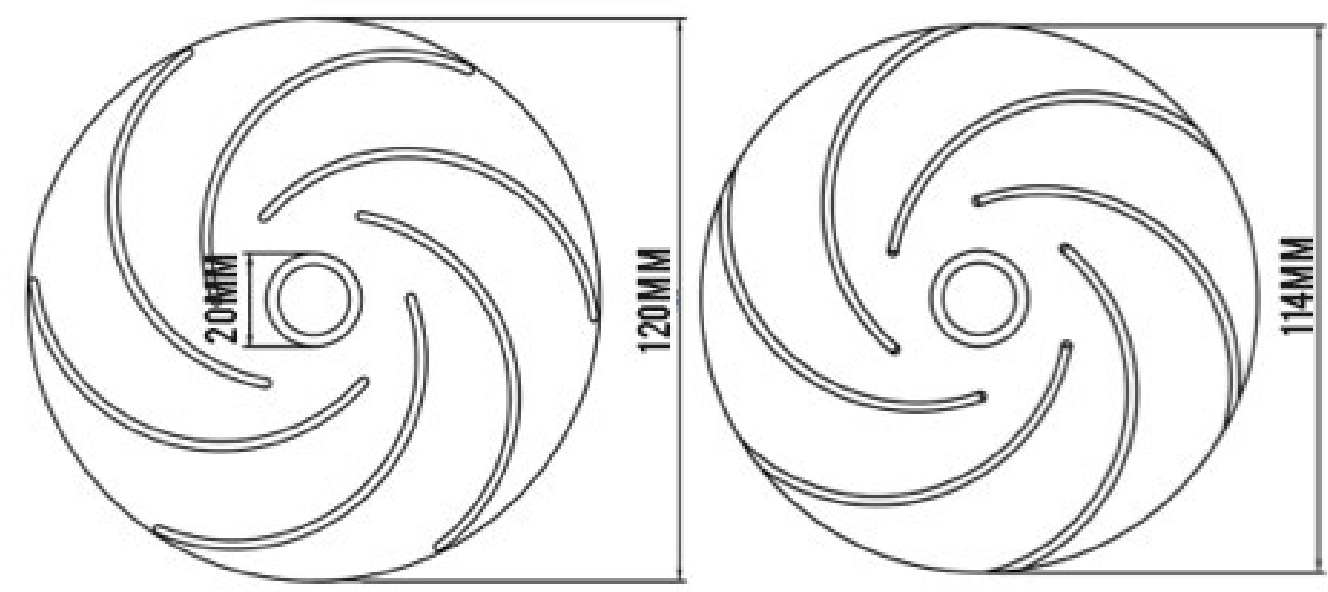

Figure 2. Backward-curved impeller with a diameter of (a) $120 \mathrm{~mm}$, (b) $114 \mathrm{~mm}$. 


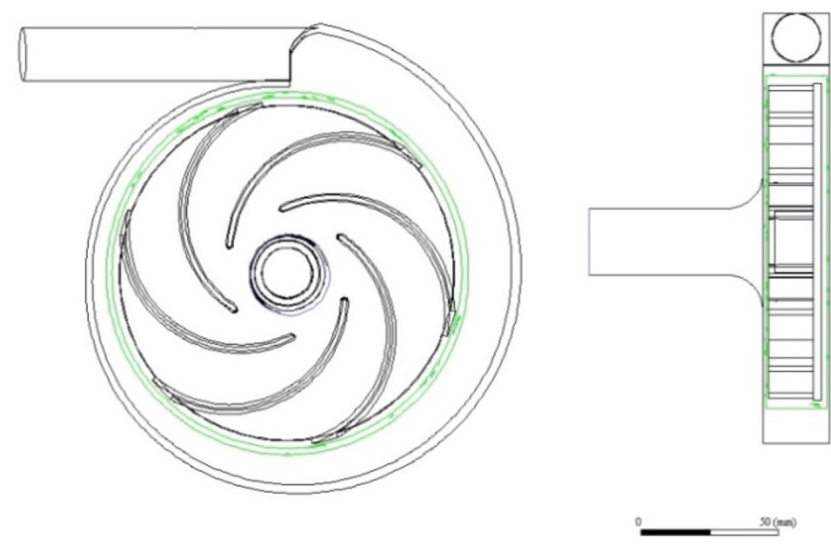

Figure 3. Simulation domain (a) front view, (b) side view.

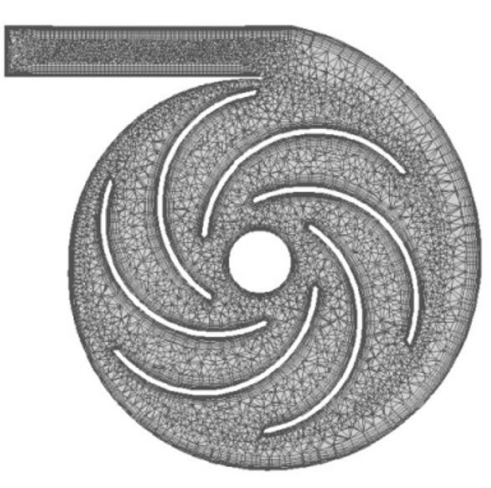

(a)

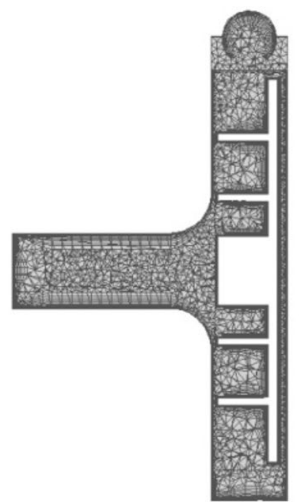

(b)

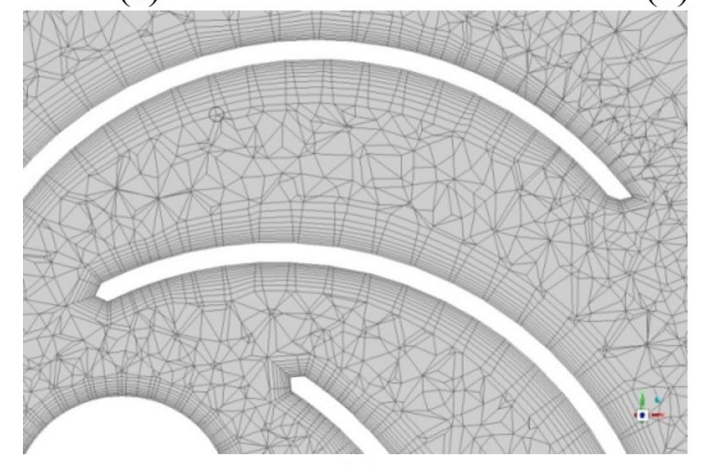

(c)

Figure 4. Meshing of the simulation domain (a) front view, (b) side view, (c) enlarged view around the impeller blades.

The boundary conditions for the incoming fluid was the velocity of the inlet, and the outflow is the outflow. For the boundary conditions of the blades and volute chamber walls is the wall. As for the boundary conditions on the walls (faces) through which the fluid passes was an interface, as shown in Figure 5. Simulations were run in ANSYS FLUENT, using a $k-\epsilon$ Realizable turbulence model with standard-wall function. The discretization scheme was second order all of the equations solved. The residual level was set to $10^{-3}$. The time step use was $8 \times 10^{-4} \mathrm{~s}$.
The calculation of the pump performance includes the head pump and the hydraulic power of the pump. If the elevation difference between the discharge and suction ports is $\Delta z$, the total head pump head, $H_{\text {pump }}$, can be calculated using Equation 1 .

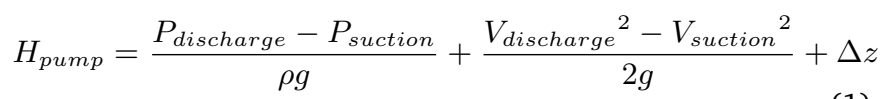




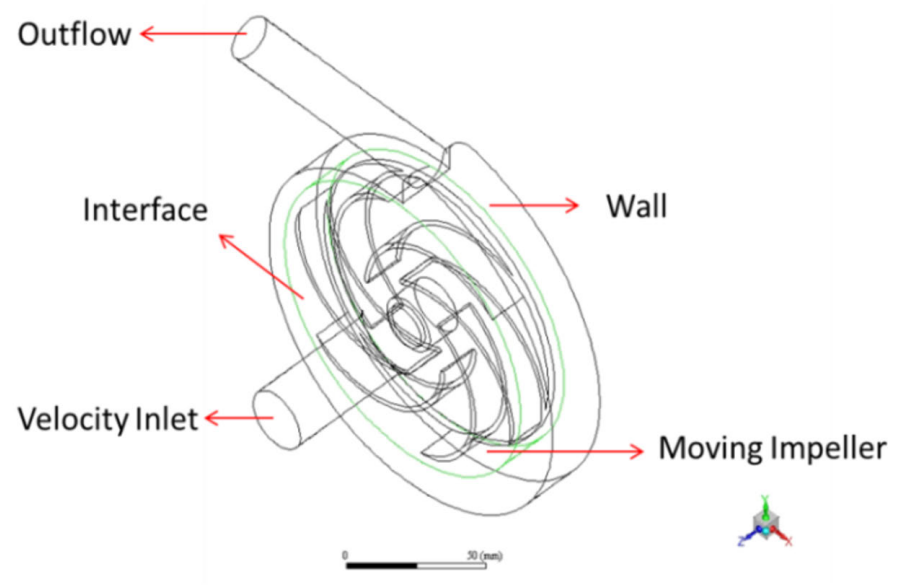

Figure 5. Geometry Boundary Conditions.

with $\rho$ is the fluid density and $g$ is the gravitational acceleration. If the head pump, $H$, and the flow capacity, $Q$, are known, then the hydraulic power calculation, WHP, is calculated using Equation 2.

$$
W H P=\rho \cdot g \cdot Q \cdot H_{p u m p}
$$

\section{Results}

\subsection{Static Pressure Contour Analysis}

Figure 6 shows the pressure contours at each variation of the capacity and variation of the pump impeller. The static pressure with the smallest value was located in the suction area, and the static pressure with the largest value was located in the area before exiting the volute. However, if observed in more detail, there was a change in the static pressure contour when the fluid led to dif- ferent discharge pumps. It can be seen that the value of static pressure on the inlet and outlet sides was getting smaller along with the increase in pump discharge. In the standard impeller, the pressure at the maximum discharge before exiting the volute was very large. It can be seen that there was a difference in pressure before exiting the volute and after passing through the discharge pipe. There was a fairly large pressure drop due to a reduction in the cross-sectional area so that the pressure drops, but at the minimum discharge, the pressure before exiting the volute was almost the same as the pressure on the discharge pipe, which means that the pressure drop at that capacity was quite low. The high pressure before discharge and the low pressure in the area between the impeller's blades resulted in circulating flow, which will be seen in the discussion of the relative velocity vectors.

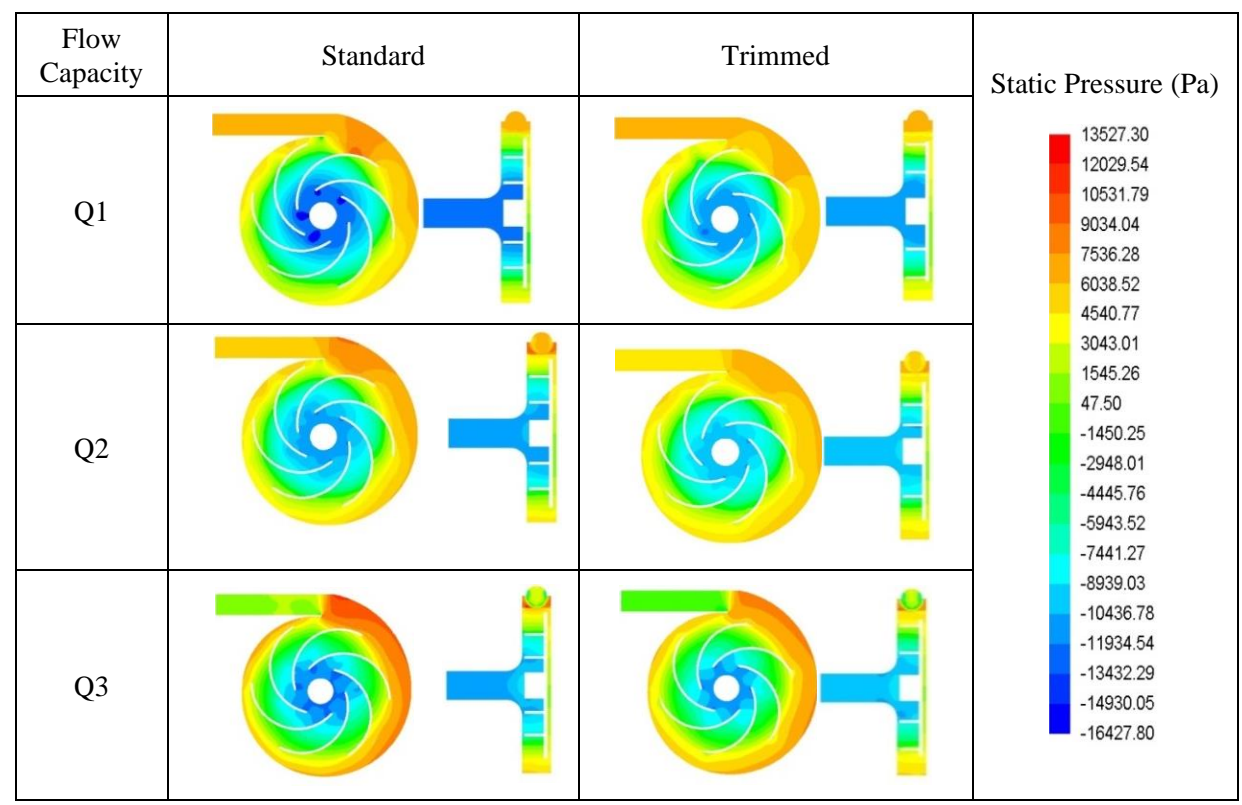

Figure 6. Static pressure contour. 
The inlet side pressure was higher on the trimmed impeller after trimming, but the outlet side was lower than the standard impeller. The difference was only visible from the color of the contours. The pressure in the volute area before leaving the discharge pipe on the impeller after trimming was lower than the initial impeller. In the trimmed impeller, the area between the volute and the impeller was larger resulted in smaller differences than before trimming. High pressure before discharge and low pressure in the area between the impeller's blades caused a circulating flow.

\subsection{Velocity Magnitude Contour Analysis}

Figure 7 shows the velocity magnitude contours at each variation of the capacity and variation of the pump impeller. It can be seen that the velocity at the inlet and on the outlet side increased with increasing pump flow capacity. If the pump discharge increased, the velocity at the outlet side would increase as well. This was indicated by the change in the color of the contours in the table. It can also be observed that the minimum velocity occurred at the suction impeller, while the maximum velocity occurred in the area near the discharge between the blades of the impeller. This was because the impeller discharge area was where the fluid would experience a change in energy, from the kinetic energy in the form of velocity to pressure when it followed the volute.

The presence of impeller trimming reduced highspeed areas. It can be seen from the color contour shown in Figure 7 for the impeller with a standard diameter, the area with high velocity was near the discharge between the blades of the impeller, while after trimming, the area had a lower velocity than before trimming, due to the longer distance between the pump housing and the impeller. Based on the velocity triangle, trimming the impeller results in a decrease in the value of the tangential velocity, $U$, in which the tangential velocity is directly proportional to the impeller radius. When the impeller diameter is smaller, the resulting tangential velocity, $U$, is smaller, and thus resulting in a decrease in absolute velocity.

\subsection{Relative Velocity Vector Analysis}

In order to analyze the circulation in the blade passage, the relative velocity vector of a pump simulation shown in Figure 8 . It can be seen that the flow circulation between the impeller blades occurred only at the standard impeller. This was because the distance between the volute and the impeller is very small, so that the velocity between the impeller and the discharged output volute was very high, seen from the velocity contours that have been discussed previously, resulting in very low pressure in that area so that it caused flow circulation due to the pressure difference. After trimming, it can be seen that there the flow circulation between the blades of the impeller was reduced. As can be seen in the velocity contour, the flow velocity distribution was quite good. There was no prominent color change between the impeller and the discharge area. This was probably because the distance between the impeller and the volute was longer than before trimming, so the possibility of recirculation losses was less.

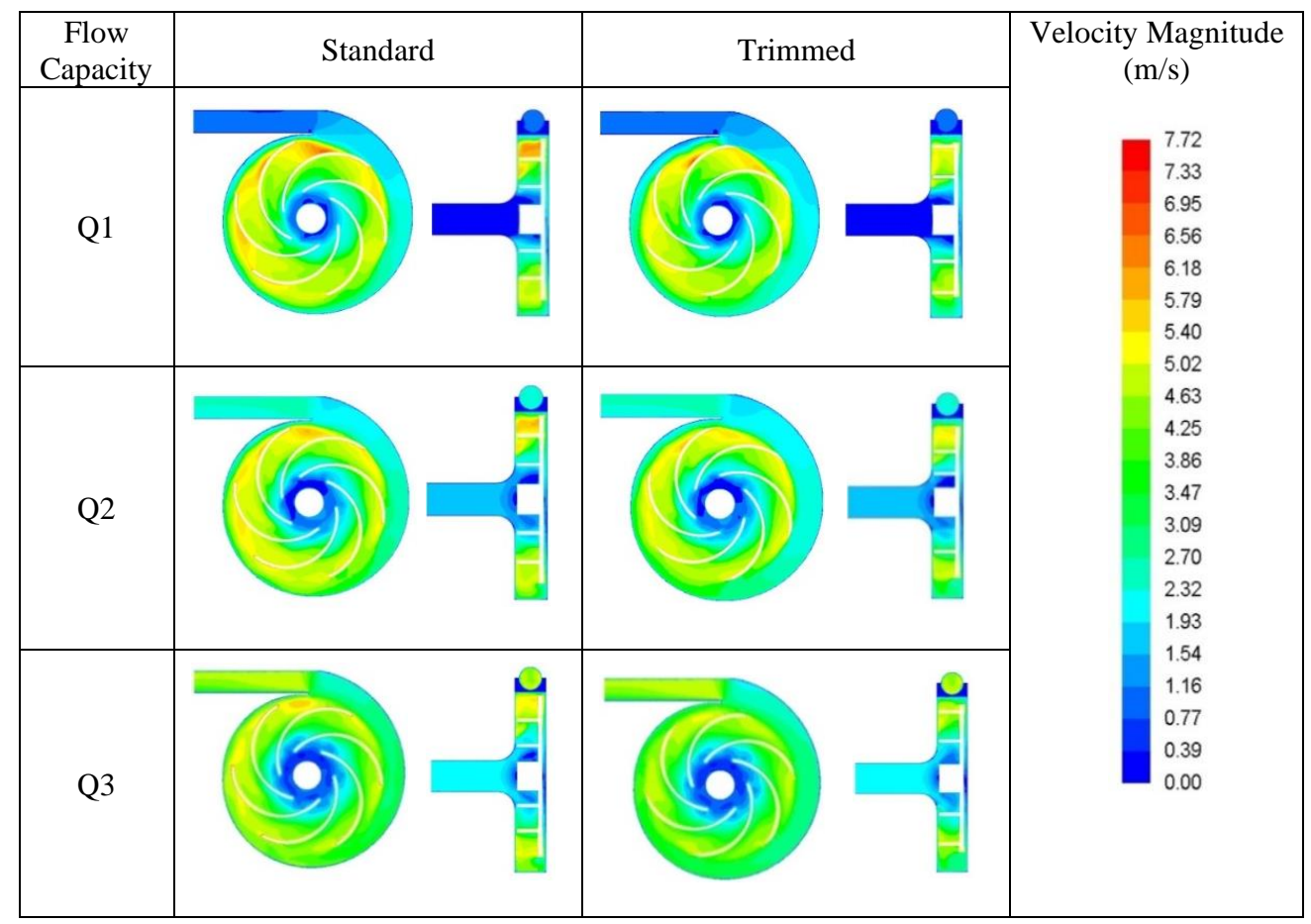

Figure 7. Velocity magnitude contour. 

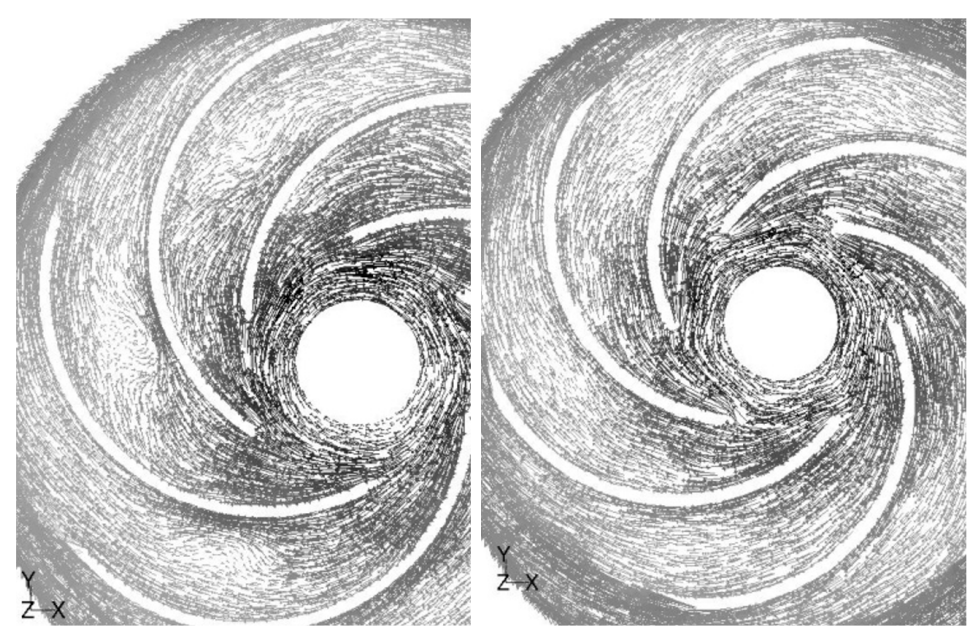

Figure 8. Relative velocity vector at maximum discharge (a) Standard (b) Trimmed.

\subsection{Head Pump and Hydraulic Power}

Table 2 shows the quantitative value from the simulations. Because the simulation was carried out transiently, the value of the suction and discharge pressure varied. The pressure values shown in Table 2 are the average values obtained from one impeller rotation.

The head pump of the simulation is compared with that of the experiment. Calculations were performed using the average value of the resulting simulation data. Fig- ure 9 shows the head of each impeller at one full rotation for various flow capacity. From the data obtained at each rotation, the suction and discharge pressure tended to fluctuate, so that the head value also fluctuated at each position of the rotation angle $(\theta)$. In general, the head of the trimmed impeller was lower than that of the standard impeller. It is shown as well that the fluctuation amplitude is greater in the low flow capacity, and reduced when the flow capacity increased.

Table 2. Average quantitave value at the suction and discharge of the pump.

\begin{tabular}{|c|c|c|c|c|c|c|}
\hline Impeller type & Flow capacity $(\mathrm{L} / \mathrm{s})$ & $\begin{array}{c}\mathrm{V}_{\text {suction }} \\
(\mathrm{m} / \mathrm{s})\end{array}$ & $\begin{array}{c}\mathrm{V}_{\text {discharge }} \\
(\mathrm{m} / \mathrm{s})\end{array}$ & $\mathrm{P}_{\text {suction }}(\mathrm{kPa})$ & $\begin{array}{c}\mathrm{P}_{\text {discharge }} \\
(\mathrm{kPa})\end{array}$ & $\Delta P(\mathrm{kPa})$ \\
\hline \multirow{3}{*}{ Standard } & 0.1 & 0.25 & 0.47 & -12.76 & 8.64 & 21.4 \\
\cline { 2 - 7 } & 0.6 & 1.32 & 2.49 & -11.09 & 6.08 & 17.17 \\
\cline { 2 - 7 } & 1 & 2.21 & 4.15 & -11.22 & -1.32 & 9.9 \\
\hline \multirow{3}{*}{ Trimmed } & 0.1 & 0.25 & 0.47 & -14.56 & 10.27 & 24.83 \\
\cline { 2 - 7 } & 0.6 & 1.32 & 2.49 & -12.74 & 7.90 & 20.64 \\
\cline { 2 - 7 } & 1 & 2.21 & 4.15 & -12.48 & 0.80 & 13.28 \\
\hline
\end{tabular}

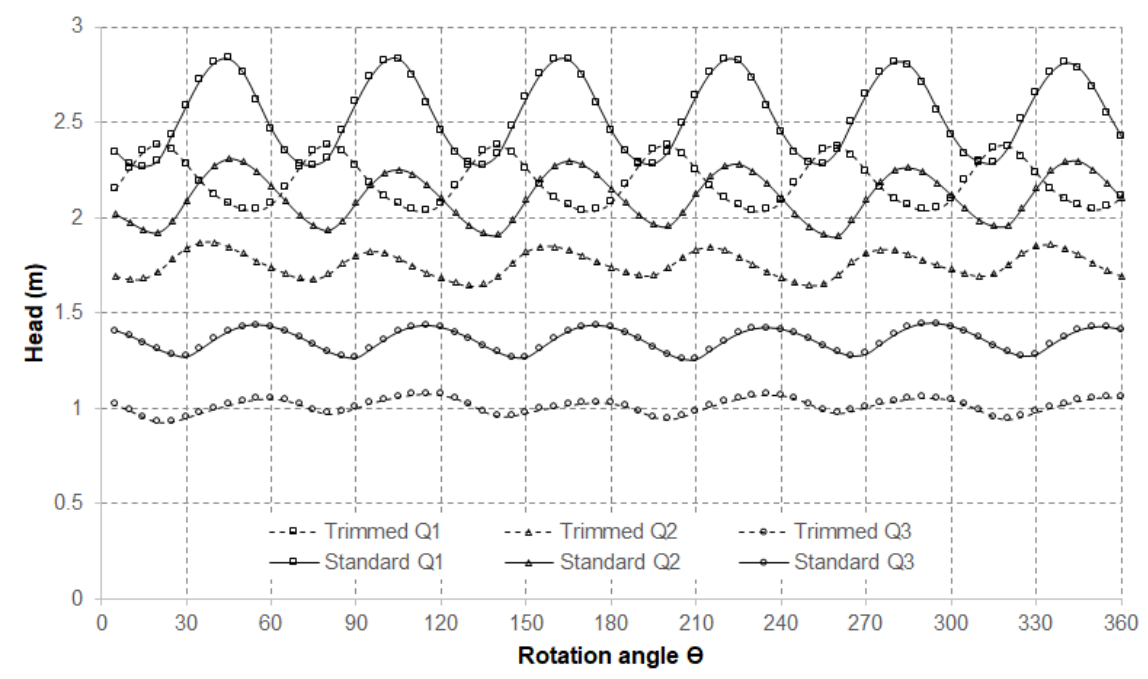

Figure 9. Head as a function of rotation angle $(\theta)$. 
Figure 10 shows the head pump as a function of flow capacity for the trimmed and standard impeller. The head curve was decreasing from low to higher capacity. It can be seen that trimmed impeller has lower head compared to the standard one. In general, head from the simulation result was lower than that of the experimental result. For the lowest flow capacity, the difference between the simulation and the experiment was about $17 \%$. The difference became more significant at higher flow capacity. This simulation might overpredict the losses in impeller, particularly at high flow capacity, and thus underestimated the head value.

The hydraulic power of the pump is shown in Figure 11. In general, the hydraulic power curve was increasing from low to higher capacity. The difference between the simulation results and the experimental results was that all the hydraulic power curves obtained from the simulation results were lower than the hydraulic power of the experimental results. Analog to the head curve, the hydraulic power was underestimated at high flow capacity.

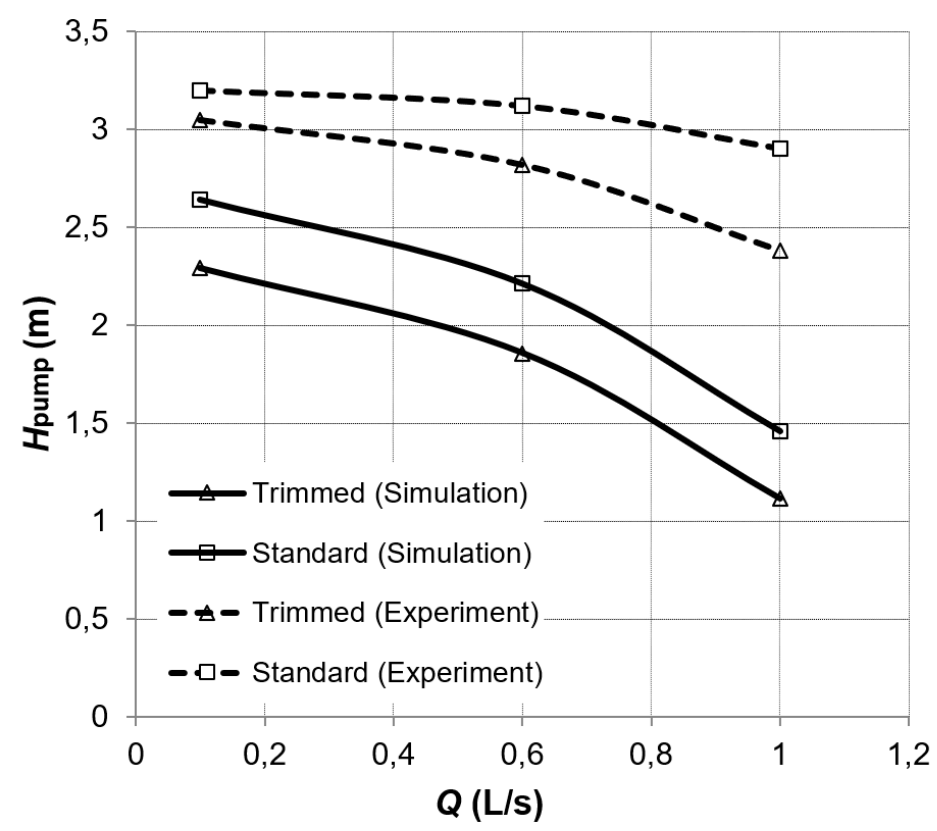

Figure 10. Head as a function of flow capacity.

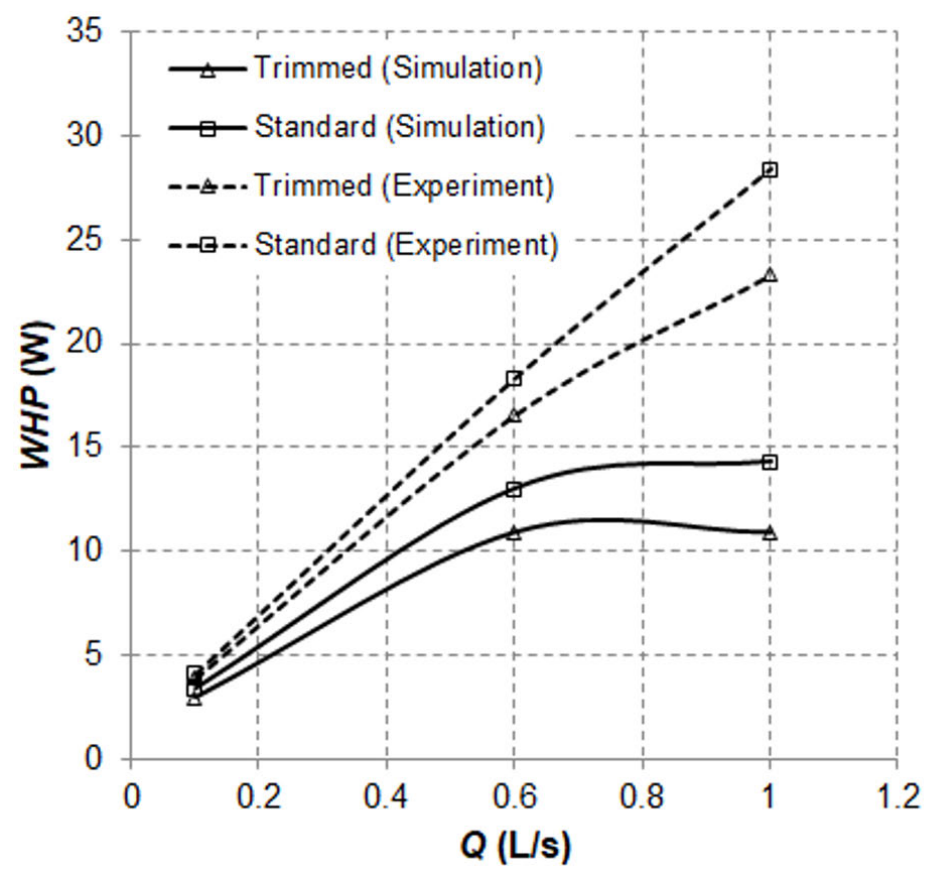

Figure 11. WHP as a function of flow capacity. 


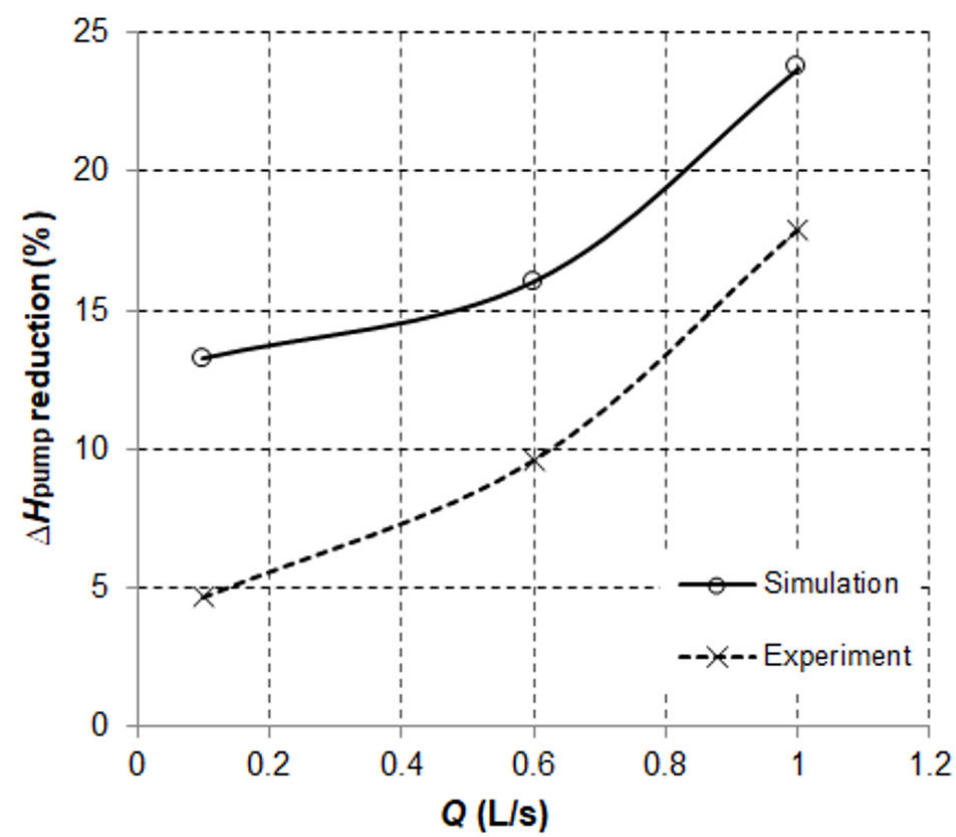

Figure 12. $\Delta H_{\text {pump }}$ reduction percentage as a function of flow capacity.

Figure 12 shows the percentage of head reduction of the trimmed impeller to the standard impeller. It can be seen that the effect of impeller trimming was greater at high flow capacity. The percentage of head reduction ranges from $13 \%$ to about $24 \%$ in the simulation, while in the experiment it ranges from about $5 \%$ to $17 \%$.

\section{Conclusion}

It can be concluded that impeller trimming reduced the head and hydraulic power when compared to the standard impeller. In the simulation, the decrease in the head and power hydraulic of the pump due to trimming the impeller from the lowest discharge to the highest discharge was about $13 \%$ to $24 \%$, comparing to the experiment results which was about $5 \%$ to $17 \%$. The simulation results tended to underpredict the head and hydraulic, particularly at high flow capacity. This might due to overprediction in flow recirculation phenomenon in the impeller passage and other hydraulic losses.

\section{References}

[1] G. Singh and J. W. Mitchell, "Energy savings from pump impeller trimming," ASHRAE journal, vol. 40, no. 4, p. 60, 1998.

[2] L. Tsang, "A theoretical account of impeller trimming of the centrifugal pump," Proceedings of the Institution of Mechanical Engineers, Part C: Journal of Mechanical Engineering Science, vol. 206, no. 3, pp. 213-214, 1992.

[3] D. G. J. Detert Oude Weme, M. S. van der Schoot, N. P. Kruyt, and E. J. J. van der Zijden, "Prediction of the Effect of Impeller Trimming on the Hydraulic Performance of Low Specific-Speed Centrifugal Pumps,"
Journal of Fluids Engineering, vol. 140, 032018. 081202.

[4] W. Guang Li, "Impeller trimming of an industrial centrifugal viscous oil pump," ADMT Journal, vol. 5, no. 1, pp. -, 2011.

[5] M. Šavar, H. Kozmar, and I. Sutlović, "Improving centrifugal pump efficiency by impeller trimming," Desalination, vol. 249, no. 2, pp. 654-659, 2009.

[6] X. Qu and L. Wang, "Effects of impeller trimming methods on performances of centrifugal pump," Journal of Energy Engineering, vol. 142, no. 4, p. 04016008, 2016.

[7] V. S. Djanali, D. S. Wahono, A. A. Wicaksono, and N. Ikhwan, "Numerical and experimental study on a backward impeller of centrifugal pump," in AIP Conference Proceedings, vol. 1983, p. 020033, AIP Publishing LLC, 2018.

[8] S. Huang, J. Guo, and F. Yang, "Numerical simulation of $3 \mathrm{~d}$ unsteady flow in a rotating pump by dynamic mesh technique," in IOP Conference Series: Materials Science and Engineering, vol. 52, p. 022030, IOP Publishing, 2013.

[9] D. Šlachtič, B. Knížat, and R. Olšiak, "CFD analysis of impeller trimming," in MATEC Web of Conferences, vol. 328, p. 02009, EDP Sciences, 2020.

[10] P. Zhou, J. Tang, J. Mou, and B. Zhu, "Effect of impeller trimming on performance," World Pumps, vol. 2016, no. 9, pp. 38-41, 2016. 
[11] A. A. Wicaksono, Studi Pengaruh Trimming Impeller Backward Single Curvature 6 Sudu Terhadap Karak- teristik Kerja Pompa Sentrifugal FM50. PhD thesis, Institut Teknologi Sepuluh Nopember, Surabaya, 2015. 